\title{
Association among subclinical hypothyroidism, TSH levels and microvascular complications in Type 2 diabetic patients
}

\author{
Feng Gao ${ }^{1}$, Nelvina Packiry Poullé2, Mohammad Ishraq Zafar ${ }^{3}$, Raja Adeel \\ Shafqat \\ Department of Endocrine, Union Hopital, Tongji Medical College, Huazhong University of Science \\ \&Technology, Wuhan, China ${ }^{1,2,3,4}$
}

\begin{abstract}
Aims: To determine whether there is an association among subclinical hypothyroidism, upper normal TSH values and microvascular complications in Type 2 diabetes.

Patients and methods: 194 Type 2 diabetic patients who were hospitalized in the Endocrinology ward of Wuhan Union Hospital, were subjected to thyroid function test ( FT3, FT4, TSH) and were screened for microvascular complications of diabetes (retinopathy, nephropathy, neuropathy).

Results: Apart from TSH levels, no significant differences were found in the clinical characteristics between the subclinical hypothyroidism and euthyroid groups. No significant difference was found in the prevalence of retinopathy, nephropathy and neuropathy in the euthyroid and subclinical hypothyroidism group $(P>0.05)$. After adjustment for potential confounding factors (age, HbAlc, duration of diabetes, gender, presence of hypertension), subclinical hypothyroidism was still not associated with retinopathy (OR 0.753, $95 \%$ CI 0.203 2.793, $P=0.671)$, nephropathy $($ OR $1.312,95 \%$ CI $0.304-5.659, P=0.716)$ and neuropathy $($ OR $0.591,95 \%$ CI $0.156-2.232, P=0.428$ ). The prevalence of microvascular complications were similar in euthyroid type 2 diabetic patients with TSH values in the upper normal range (TSH $2.00-4.94 \mu \mathrm{IU} / \mathrm{ml}$ ) and in those with lower TSH values (TSH $0.35-1.99 \mu \mathrm{IU} / \mathrm{ml})$, (P>0.05). There was no significant difference in the TSH levels of the patients who had any particular microvascular complication or a combination of them $(P=0.827)$.

Conclusion: We conclude that there is no association among subclinical hypothyroidism, upper normal TSH values and microvascular complications in type 2 diabetes.
\end{abstract}

Keywords: Subclinical hypothyroidism, TSH, Type 2 Diabetes Mellitus, Microvascular complications Abbreviations:

\section{INTRODUCTION}

Subclinical hypothyroidism ( $\mathrm{SCH}$ ) is defined as elevated thyroid stimulating hormone(TSH) levels above the upper limit of the reference range in addition to a normal free thyroxine level(FT4) [1]. The prevalence of subclinical hypothyroidism in the general population has been estimated to be 4-10\% according to large population screening surveys [2]. Subclinical hypothyroidism may increase the risk of cardiovascular events which seemed to be higher as the TSH levels increase [3].

Among type 2 diabetic patients, the prevalence of subclinical hypothyroidism ranges from 2 to $17 \%$ [4, $5,6,7$ ]. Does subclinical hypothyroidism have an effect on the complications of diabetes?

Few studies have examined the association between subclinical hypothyroidism and microvascular complications in type 2 diabetic patients and the association between TSH levels and the microvascular complications in type 2 diabetic patients.

In a study done in Taiwan by Chen et al, it was found that there was an increased prevalence of nephropathy in type 2 diabetic patients with subclinical hypothyroidism compared to those who were euthyroid. The prevalence of retinopathy was not found to be higher [5].

However in a study done by Yang et al in China, it was reported that there was an increased prevalence of retinopathy in type 2 diabetic patients with subclinical hypothyroidism and patients with a TSH level in the upper normal range (2.0-4.0 $\mu \mathrm{IU} / \mathrm{ml})$ also had a higher prevalence of severe retinopathy compared to those with lower TSH levels [8].

Kim et al from Korea, also reported that severe retinopathy was more common in type 2 diabetic patients with subclinical hypothyroidism than in those who were euthyroid, they found no significant difference in the prevalence of nephropathy [4].

According to a study done in Japan by Yasuda et al, subclinical hypothyroidism was associated with albuminuria in type 2 diabetic patients and the TSH level was found to be an independent risk factor for the presence of albuminuria [9].

Since the results of those studies were contradictory, it is necessary for us to further examine the association of subclinical hypothyroidism and the microvascular complications in type 2 diabetic patients, and to 
investigate whether upper normal TSH levels could influence the microvascular complications in type 2 diabetes.

Moreover, no study to our knowledge has examined the prevalence of neuropathy in association with subclinical hypothyroidism and upper normal TSH levels. Therefore, in the present study we have examined whether there was an association between retinopathy, nephropathy and neuropathy in type 2 diabetic patients with subclinical hypothyroidism and in those with TSH values in the upper normal range

\section{METHODS}

The 194 Chinese patients, with type 2 diabetes mellitus, who were hospitalized in the Endocrinology ward of Wuhan Union Hospital, were subjected to thyroid function test ( FT3, FT4, TSH). Patients with known overt or subclinical hypothyroidism, known overt or subclinical hyperthyroidism and type 1 diabetes mellitus were excluded from the study. Relevant data about the patients were collected including age, gender, duration of diabetes, history of hypertension, BMI, systolic and diastolic blood pressure, fasting blood glucose, HbA1c, creatinine levels, total cholesterol (TC), triglyceride (TG), HDL and LDL cholesterol. During their hospitalization the patients were screened for the microvascular complications of diabetes (retinopathy, nephropathy, neuropathy). Retinopathy was diagnosed based on the presence of microaneurysm, hemorrhage, exudates, vascular abnormalities or neovascularization detected by digital retinal photographs that were taken by Canon Digital Camera CR-2. Nephropathy was diagnosed by albuminuria determined by elevated 24 hour urine microalbumin (urinary albumin excretion $>30 \mathrm{mg} / 24 \mathrm{~h}$ ) or by elevated 24 hour urinary protein (24h urinary protein $>0.5 \mathrm{~g} / 24 \mathrm{~h}$ ). Neuropathy was diagnosed based on abnormalities detected during neuropathic screening test (vibration sense testing, temperature sense, pain perception, monofilament testing and examination of reflexes) or by nerve conduction studies done by Medtronic Keypoint/Nicolet Viking Quest. TSH, FT3 and FT4 were measured by Chemiluminescent Microparticle Immunoassay (Architect i System, Abbott Laboratories). The reference range for normal TSH was 0.35-4.94 $\mu \mathrm{IU} / \mathrm{ml}$, the reference range for normal FT3 was 2.63-5.7 $\mathrm{pmol} / \mathrm{l}$, and the reference range for normal FT4 was $9-19.8 \mathrm{pmol} / \mathrm{l}$. Of the 194 type 2 diabetic patients that were screened for thyroid function tests 16 were found to have subclinical hypothyroidism (elevated TSH levels $>4.94$ $\mu \mathrm{IU} / \mathrm{ml}$ with normal FT3 and FT4) and 177 were found to be euthyroid( normal thyroid function test). 1 patient was found to have both elevated TSH and elevated FT4 and was excluded from the analysis. All the microvascular complication screening reports were available for 106 patients during their hospital stay, 56 patients lacked retinopathy screening report, 46 patients lacked nephropathy screening report and 41 lacked report for neuropathy screening. These were accounted for during the statistical analysis by using valid percentages only. The 177 euthyroid patients were divided into 2 groups based on their TSH levels.TSH 0.35$1.99 \mu \mathrm{IU} / \mathrm{ml}$ group consisted of 106 patients. TSH $2.00-4.94 \mu \mathrm{IU} / \mathrm{ml}$ group consisted of 71 patients.

Moreover, the patients were classified according to the microvascular complication present into either retinopathy only; nephropathy only; neuropathy only; retinopathy and nephropathy; retinopathy and neuropathy; nephropathy and neuropathy; retinopathy, nephropathy and neuropathy or no microvascular complications.

\section{STATISTICAL ANALYSIS}

The statistical analysis was done using IBM SPSS Statistics version 20. Chi-square tests and T tests were used, as appropriate, to compare the differences in the characteristics of the patients in the subclinical hypothyroidism and the euthyroid group. Chi- square test was used to compare the prevalence of the microvascular complications in the different groups. Multinomial logistic regression was used to obtain the Odds ratio (OR) for retinopathy, nephropathy and neuropathy after adjustment for potential confounding factors. The mean TSH values were calculated for each microvascular complication group and the difference in TSH levels was compared using the one-way analysis of variance test (ANOVA) and post-hoc analysis.

$\mathrm{P}$ value $<0.05$ was considered to be statistically significantation.

\section{RESULTS}

The overall prevalence of subclinical hypothyroidism was $8.3 \%$ in type 2 diabetic patients. The prevalence was $4.9 \%$ in males and $12.2 \%$ in females with type 2 diabetes. The characteristics of the patients are listed in Table 1. The subclinical hypothyroidism group had a higher percentage of female patients than the euthyroid group, however it was not a statistically significant difference. As expected, TSH levels were significantly higher in the subclinical hypothyroidism group $(\mathrm{P}<0.001)$. No significant differences were found in the other characteristics between groups.

No significant difference was found in the prevalence of retinopathy, nephropathy and neuropathy in the euthyroid and subclinical hypothyroidism group $(\mathrm{P}>0.05)$, as shown in Table 2 . After adjustment for potential confounding factors (age, HbA1c, duration of diabetes, gender, presence of hypertension), subclinical hypothyroidism was still not associated with retinopathy (OR $0.753,95 \%$ CI $0.203-2.793, \mathrm{P}=0.671$ ), nephropathy $(\mathrm{OR} 1.312,95 \%$ CI $0.304-5.659, \mathrm{P}=0.716)$ and neuropathy $(\mathrm{OR} 0.591,95 \%$ CI $0.156-2.232$, 
$P=0.428)$, as shown in Table 3. The prevalence of microvascular complications were similar in euthyroid type 2 diabetic patients whose TSH values were in the upper normal range (TSH $2.00-4.94 \mu \mathrm{IU} / \mathrm{ml}$ ) and in those with lower TSH values (TSH $0.35-1.99 \mu \mathrm{IU} / \mathrm{ml})$, ( $>>0.05)$, as shown in Table 4 . There was no significant difference in the TSH levels of the patients who had any particular microvascular complication or a combination of them $(\mathrm{P}=0.827$ by ANOVA test $)$ as shown in Table 5 .

\section{DISCUSSION}

The prevalence of subclinical hypothyroidism in the present study was found to be $8.3 \%$ in type 2 diabetic patients, which is almost the same as that reported from studies done on the general population [2] and the same as that reported in previous studies done on type 2 diabetic patients $[4,5,6,7]$. In the present study, the prevalence of subclinical hypothyroidism was $4.9 \%$ in male patients and $12.2 \%$ in female patients.

Vascular endothelial dysfunction is believed to be an important factor in the pathogenesis of microvascular and macrovascular complications in diabetes. Endothelial dysfunction in Type 2 DM occurs as a result of hyperglycemia, growth factors, vasoactive agents, and components of metabolic syndrome [10]. Endothelial dysfunction has also been reported in subclinical hypothyroidism as well as well as in those with upper normal TSH values $[11,12,13,14]$. The association between microvascular complications and subclinical hypothyroidism and TSH values has not been extensively investigated. Among the few studies done on the subject, the findings have been contradictory. Chen et al reported an association between subclinical hypothyroidism and nephropathy but no association with retinopathy was found [5]. Yasuda et al, found an association between subclinical hypothyroidism and albuminuria [9]. Yang et al, on the other hand, reported an association between retinopathy and subclinical hypothyroidism and with those with TSH values in the high upper normal range (2.0-4.0 $\mu \mathrm{IU} / \mathrm{ml})$ [8]. Kim et al reported an association between subclinical hypothyroidism and retinopathy but no association with nephropathy [4].

In our present study we did not find any association between subclinical hypothyroidism and microvascular complications in type 2 diabetes (retinopathy, nephropathy, neuropathy).

Moreover, in patients with TSH values in the upper normal range (TSH 2.00-4.94 $\mu \mathrm{IU} / \mathrm{ml}$ ), the risk of microvascular complications was the same as in those with lower TSH values, and no difference in TSH level was found between patients with any particular microvascular complication or a combination of microvascular complications.

The reasons why our results showed no significant relationship among subclinical hypothyroidism, TSH levels and microvascular complications could be because hyperglycemia $[15,16,17,18,19,20]$, as opposed to TSH levels, is the main factor responsible for the development of microvascular complications in type 2 diabetic patients. Secondly, the TSH levels in our study were probably not high enough to influence the microvascular complications.

Based on our findings, we conclude that there is no association between subclinical hypothyroidism and upper normal TSH values with microvascular complications in type 2 diabetes.

Therefore, according to the results of our study, routine screening of thyroid function in type 2 diabetic patients is not warranted; and the treatment of subclinical hypothyroidism might not have a considerable effect on the prevention or clinical course of microvascular complications in type 2 diabetes.

However, since the present study is only an observational study, a controlled trial should be done to further establish the role of routine screening and treatment of subclinical hypothyroidism in type 2 diabetic patients.

According to Chu and Crapo, unless specific clinical circumstances (TSH $>10 \mathrm{mU} / \mathrm{l}$ on repeated measurements, symptomatic, family history of thyroid disease, pregnancy, smoking, dyslipidemia), it is unnecessary to treat most patients with subclinical hypothyroidism and it would not be of much benefit [21].

However, for the prevention of macrovascular complications of type 2 diabetes, treatment should be considered. According to the ATA/AACE, patients with TSH levels more than $10 \mathrm{mIU} / \mathrm{L}$ should be treated with L-thyroxine because of the increased risk of heart failure and death from cardiovascular causes. They also recommend to consider treatment for patients whose TSH levels fall between the upper limit of normal and 10 $\mathrm{mIU} / \mathrm{L}$, if the patients are symptomatic, positive for thyroid autoantibodies, have a history of atherosclerotic cardiovascular disease, heart failure or have other risk factors [1].

The limitations of the study include: firstly, the study was done on Chinese patients from a single hospital only, therefore the results may not fully describe the entire Chinese population. Secondly thyroid function tests were done only once during hospitalization. According to previous studies, some patients found to have subclinical hypothyroidism may progress to overt hypothyroidism or they may become euthyroid on follow up thyroid function tests $[22,23]$. Thirdly, the study was observational in nature, therefore a controlled study would be more appropriate to confirm the association of subclinical hypothyroidism and microvascular complications and to establish whether routine screening and treatment of subclinical hypothyroid patients would be appropriate. Moreover, the screening tests for microvascular complications were done only once, 
ideally these should have been repeated for confirmation, for instance, and diagnosis of diabetic nephropathy should be made after having tested for urinary albumin excretion at least 3 times [24].

\section{Acknowledgements}

We wish to thank Professor Chen Lu-Lu for allowing us to include patients under her care in the study and we wish to thank the doctors and nursing staff of the Endocrinology ward of Wuhan Union Hospital for their help and support.

\section{Tables}

Table 1 Characteristics of the type 2 diabetic patients who were euthyroid or who had subclinical hypothyroidism

\begin{tabular}{|c|c|c|c|}
\hline & Euthyroid( n=177) & $\begin{array}{l}\text { Subclinical hypothyroidism } \\
(\mathrm{n}=16)\end{array}$ & P value \\
\hline Age (years) & $56.32 \pm 13.3$ & $59.13 \pm 12.9$ & 0.417 \\
\hline Presence of hypertension (\%) & 68.3 & 68.8 & 0.968 \\
\hline BMI $\left(\mathrm{kg} / \mathrm{m}^{2}\right)$ & $24.9 \pm 4.3$ & $25.1 \pm 3.6$ & 0.846 \\
\hline Systolic blood pressure (mmHg) & $134.1 \pm 82.4$ & $132.6 \pm 18.6$ & 0.946 \\
\hline $\operatorname{HbA1c}(\%)$ & $8.8 \pm 2.3$ & $8.4 \pm 2.5$ & 0.490 \\
\hline Fasting blood glucose $(\mathrm{mmol} / \mathrm{l})$ & $8.7 \pm 4.2$ & $7.5 \pm 4.1$ & 0.311 \\
\hline Creatinine $(\mu \mathrm{mol} / \mathrm{l})$ & $72.7 \pm 40.9$ & $95.0 \pm 72.0$ & 0.255 \\
\hline Total cholesterol (mmol/l) & $4.60 \pm 1.31$ & $4.27 \pm 0.81$ & 0.355 \\
\hline Triglyceride $(\mathrm{mmol} / \mathrm{l})$ & $2.08 \pm 1.96$ & $1.62 \pm 1.52$ & 0.375 \\
\hline HDL cholesterol (mmol/l) & $1.24 \pm 0.31$ & $1.39 \pm 0.37$ & 0.066 \\
\hline $\mathrm{TSH}(\mu \mathrm{IU} / \mathrm{ml})$ & $1.877 \pm 0.972$ & $7.707 \pm 4.767$ & $<0.001$ \\
\hline
\end{tabular}

Characteristics listed as mean \pm SD. P values were obtained by Chi-square test or T test. BMI, Body Mass Index; HDL, High Density Lipoprotein; LDL, Low Density Lipoprotein.

Table 2 Prevalence of Retinopathy, Nephropathy and Neuropathy in type 2 diabetic patients who were euthyroid or who had subclinical hypothyroidism

\begin{tabular}{|l|c|c|r|}
\hline & Euthyroid (n= 177) & $\begin{array}{l}\text { Subclinical hypothyroidism } \\
(\mathbf{n = 1 6})\end{array}$ & P value \\
\hline Retinopathy (\%) & 50 & 50 & 0.979 \\
\hline Nephropathy (\%) & 37 & 40 & 0.827 \\
\hline Neuropathy (\%) & 35 & 36 & 0.944 \\
\hline
\end{tabular}

$\mathrm{P}$ values were obtained by Chi-square test

Table 3 Multinomial logistic regression for the presence of retinopathy, nephropathy and neuropathy in type 2 diabetic patients

\begin{tabular}{|c|c|c|c|}
\hline Independent variable & Odds ratio & $95 \% \mathrm{CI}$ & P value \\
\hline \multicolumn{4}{|l|}{ Retinopathy present } \\
\hline Age (years) & 1.007 & $0.968-1.047$ & 0.732 \\
\hline HbA1c (\%) & 1.028 & $0.878-1.202$ & 0.734 \\
\hline Duration of diabetes (years) & 1.043 & $0.965-1.127$ & 0.285 \\
\hline Gender (Female) & 1.041 & $0.484-2.241$ & 0.918 \\
\hline Hypertension (present) & 1.446 & $0.656-3.188$ & 0.360 \\
\hline Subclinical hypothyroidism & 0.753 & $0.203-2.793$ & 0.671 \\
\hline Euthyroid & 1.328 & $0.358-4.922$ & 0.671 \\
\hline \multicolumn{4}{|l|}{ Nephropathy present } \\
\hline Age (years) & 1.005 & $0.964-1.047$ & 0.823 \\
\hline $\operatorname{HbA1c}(\%)$ & 1.280 & $1.021-1.605$ & 0.027 \\
\hline Duration of diabetes (years) & 1.085 & $0.997-1.181$ & 0.052 \\
\hline Gender (Female) & 0.700 & $0.277-1.771$ & 0.450 \\
\hline Hypertension (present) & 22.914 & $4.795-109.506$ & $<0.001$ \\
\hline Subclinical hypothyroidism & 1.312 & $0.304-5.659$ & 0.716 \\
\hline Euthyroid & 0.762 & $0.177-3.287$ & 0.716 \\
\hline \multicolumn{4}{|l|}{ Neuropathy present } \\
\hline Age (years) & 1.054 & $1.011-1.100$ & 0.012 \\
\hline $\mathrm{HbA1c}(\%)$ & 1.183 & $0.989-1.416$ & 0.059 \\
\hline Duration of diabetes (years) & 1.067 & $0.990-1.148$ & 0.084 \\
\hline
\end{tabular}


Association among subclinical hypothyroidism, TSH levels and microvascular complications in T2DM

\begin{tabular}{|l|c|c|c|}
\hline Gender (Female) & 1.946 & $0.864-4.380$ & 0.106 \\
\hline Hypertension (present) & 1.593 & $0.629-4.037$ & 0.321 \\
\hline Subclinical hypothyroidism & 0.591 & $0.156-2.232$ & 0.428 \\
\hline Euthyroid & 1.693 & $0.448-6.399$ & 0.428 \\
\hline
\end{tabular}

Table 4 Prevalence of Retinopathy, Nephropathy and Neuropathy in euthyroid type 2 diabetic patients with upper normal TSH values and in those with lower TSH values

\begin{tabular}{|c|c|c|c|}
\hline & $\begin{array}{c}\text { TSH 0.35-1.99 } \boldsymbol{\mu I U} / \mathbf{m l} \\
(\mathbf{n = 1 0 6})\end{array}$ & $\begin{array}{c}\text { TSH 2.00-4.94 } \boldsymbol{\mu I U} / \mathbf{m l} \\
(\mathbf{n = 7 1})\end{array}$ & P value \\
\hline Retinopathy (\%) & 51 & 48 & 0.770 \\
\hline Nephropathy (\%) & 37 & 38 & 0.870 \\
\hline Neuropathy (\%) & 30 & 41.4 & 0.166 \\
\hline
\end{tabular}

$\mathrm{P}$ values were obtained by Chi-square test

Table 5 Mean TSH values of type 2 diabetic patients with any particular microvascular complication, a combination of microvascular complications or no microvascular complication

\begin{tabular}{|l|l|}
\hline Microvascular complication & TSH $(\boldsymbol{\mu I U} / \mathbf{m l})$ \\
\hline Retinopathy only $(\mathrm{n}=18)$ & $1.88 \pm 1.37$ \\
\hline Nephropathy only $(\mathrm{n}=5)$ & $1.85 \pm 1.87$ \\
\hline Neuropathy only $(\mathrm{n}=11)$ & $2.65 \pm 1.89$ \\
\hline Retinopathy and Nephropathy $(\mathrm{n}=8)$ & $2.11 \pm 1.84$ \\
\hline Retinopathy and Neuropathy $(\mathrm{n}=8)$ & $2.76 \pm 2.23$ \\
\hline Nephropathy and Neuropathy $(\mathrm{n}=2)$ & $1.70 \pm 0.42$ \\
\hline Retinopathy, Nephropathy and Neuropathy $(\mathrm{n}=16)$ & $2.89 \pm 2.92$ \\
\hline No microvascular complication $(\mathrm{n}=38)$ & $2.38 \pm 1.70$ \\
\hline
\end{tabular}

TSH values listed as mean \pm SD. $\mathrm{P}=0.827$ for the difference in TSH levels among groups obtained by the one-way analysis of variance test (ANOVA)

\section{REFERENCES}

[1] ATA/AACE Guidelines CLINICAL PRACTICE GUIDELINES FOR HYPOTHYROIDISM IN ADULTS: COSPONSORED BY THE AMERICAN ASSOCIATION OF CLINICAL ENDOCRINOLOGISTS AND THE AMERICAN THYROID ASSOCIATION, Endo Pract. 2012;18(No.6)

[2] McDermott MT,Ridgway EC: Subclinical hypothyroidism is mild thyroid failure and should be treated. J ClinEndocrinolMetab 2001; 86: 4585- 4590

[3] Rodondi N, den Elzen WP, Bauer DC, Cappola AR, Razvi S, et al. Subclinical hypothyroidism and the risk of coronary heart disease and mortality. JAMA. 2010;304:1365-1374.

[4] Kim BY, Kim CH, Jung CH, Mok JO, Suh KI, Kang SKAssociation between subclinical hypothyroidism and severe diabetic retinopathy in Korean patients with type 2 diabetes.Endocr J. 2011;58(12):1065-70

[5] Chen, H.-S., Wu, T.-E. J., Jap, T.-S., Lu, R.-A., Wang, M.-L., Chen, R.-L.and Lin, H.-D. (2007), Subclinical hypothyroidism is a risk factor for nephropathy and cardiovascular diseases in Type 2 diabetic patients. Diabetic Medicine, 24: 1336-1344.

[6] Perros P, McCrimmon RJ, Shaw G, Frier BM. Frequency of thyroid dysfunction in diabetic patients: value of annual screening.Diabet Med 1995; 12: 622-627

[7] Smithson MJ. Screen for thyroid dysfunction in community population of diabetic patients. Diabet Med 1998; 15: 148-150.

[8] Yang JK, Liu W, Shi J, Li YB LiAn Association Between Subclinical Hypothyroidism and Sight-Threatening Diabetic Retinopathy in Type 2 Diabetic PatientsDiabetes Care May 2010 vol. 33 no. 5 1018-1020

[9] Yasuda T, Kaneto H, Kuroda A, Yamamoto T, Takahara M, Naka T, Miyashita K, Fujisawa K, Sakamoto F, Katakami N, Matsuoka TA, Shimomura ISubclinical hypothyroidism is independently associated with albuminuria in people with type 2 diabetes. Diabetes Res ClinPract. 2011 Dec;94(3):e75-77

[10] C.G. Schalkwijk and C.D. Stehouwer, Vascular complications in diabetes mellitus: the role of endothelial dysfunction. ClinSci (Lond), 109 (2005), pp. 143-159.

[11] Cikim AS, Oflaz H, Ozbey N, Cikim K, Umman S,Meric M, Sencer E, Molvalilar S (2004) Evaluation of endothelial function in subclinical hypothyroidism andsubclinical hyperthyroidism. Thyroid 14: 605-609

[12] La Vignera S, Condorelli R, Vicari E, Calogero AE Endothelial dysfunction and subclinical hypothyroidism: a brief reviewJEndocrinol Invest. 2012 Jan;35(1):96-103.

[13] B. Biondi, M. Galderisi, L. Pagano, M. Sidiropulos, M. Pulcrano and A. D'Errico, et al. Endothelial-mediated coronary flow reserve in patients with mild thyroid hormone deficiency. Eur J Endocrinol, 161 (2009), pp. 323-329.

[14] [SemraBaycan, DoganErdogan, Mustafa Caliskan, BarisOnderPamuk,OzgurCiftci,HakanGullu, AylinYildirir, Nilgun D. Guvener,HaldunMuderrisogluCoronary Flow Reserve Is Impaired in Subclinical Hypothyroidism. Clin.Cardiol.2007; 30: 562-566.

[15] ADVANCE Collaborative Group, Patel A, MacMahon S, Chalmers J, Neal B, Billot L, Woodward M, Marre M, Cooper M, Glasziou P, Grobbee D, Hamet P, Harrap S, Heller S, Liu L, Mancia G, Mogensen CE, Pan C, Poulter N, Rodgers A, Williams B, Bompoint S, de Galan BE, Joshi R, Travert F. Intensive blood glucose control and vascular outcomes in patients with type 2 diabetes. N Engl J Med. 2008 Jun 12;358(24):2560-72

[16] Y Ohkubo, H Kishikawa, E Araki et al. Intensive insulin therapy prevents the progression of diabetic microvascular complications in Japanese patients with non-insulin-dependent diabetes mellitus: a randomized prospective 6-year study Diabetes Res Clin Pract, 28 (1995), pp. 10

[17] Ismail-Beigi F, Craven T, Banerji MA, Basile J, Calles J, Cohen RM, Cuddihy R, Cushman WC, Genuth S, Grimm RH Jr, Hamilton BP, Hoogwerf B, Karl D, Katz L, Krikorian A, O'Connor P, Pop-Busui R, Schubart U, Simmons D, Taylor H, Thomas A, Weiss D, Hramiak I; ACCORD trial group. Effect of intensive treatment of hyperglycaemia on microvascular outcomes in type 2 diabetes: an analysis of the ACCORD randomised trial. Lancet. 2010 Aug 7;376(9739):419-30. 
[18] M. Loredana Marcovecchio, Marta Lucantoni, and Francesco Chiarelli. Diabetes Technology \& Therapeutics. March 2011, 13(3): 389-394.

[19] Cristina Bianchi, Stefano Del Prato. Metabolic Memory and Individual Treatment Aims in Type 2 Diabetes - Outcome-Lessons Learned from Large Clinical Trial. Rev Diabet Stud, 2011, 8(3):432-440

[20] Hari KVS Kumar, SK Kota, A Basile, KD Modi Profile of Microvascular Disease in Type 2 Diabetes in a Tertiary Health Care Hospital in India. Ann Med Health Sci Res. 2012 Jul-Dec; 2(2): 103-108.

[21] Chu JW, Crapo LM. The treatment of subclinical hypothyroidism is seldom necessary. J Clin Endocrinol Metab 2001; 86:45914599

[22] Parle JV, Franklyn JA, Cross KW, Jones SC, Sheppard MC (1991) Prevalence and follow-up of abnormal thyrotrophin (TSH) concentrations in the elderly in the United Kingdom. Clin Endocrinol (Oxf) 34: 77-83.

[23] Diez JJ, Iglesias P (2004) Spontaneous subclinical hypothyroidism in patients older than 55 years: an analysis of natural course and risk factors for the development of overt thyroid failure. J Clin Endocrinol Metab 89: 4890-4897.

[24] American Diabetes Association Standards of Medical Care in Diabetes-2013. Diabetes Care Volume 36, Supplement 1, January 2013 